\title{
THE EFFECT OF SQUEEZE PIN DIMENSION AND OPERATIONAL PARAMETERS ON MATERIAL HOMOGENITY OF ALUMINIUM HIGH PRESSURE DIE CAST PARTS
}

\author{
Ferencz PETI ${ }^{1}$, Gabriela STRNAD ${ }^{2}$ \\ ${ }^{1,2}$ George Emil Palade University of Medicine, Pharmacy, Science, and Technology of Targu Mures, \\ Faculty of Engineering and Information Technology, N. Iorga street, no. 1, Targu Mures, Romania \\ 1ferencz.peti@umfst.ro \\ 2gabriela.strnad@umfst.ro
}

\begin{abstract}
The present paper is an experimental study on the squeeze pin effect on the high pressure die cast aluminium parts, as a way of improvement of material homogenity on various and big wall thickness castings. Squeeze is used in high pressure die casting technology for optimizing homogenity of big wall thicknesses of die cast parts working as structural, mechanical and hydraulic components, made of different aluminium alloys such AlSi alloys. The objective of this research is to highlight the primary and secondary effects of squeezing on the structural homogenity of high pressure die cast aluminium parts, as well as the dependence of the effects on the squeeze pin dimensions and the operating parameters.
\end{abstract}

Key words: high pressure die casting, AlSi alloy, squeeze pin, shrinkage, cold flow, porosity

\section{Introduction}

High pressure die-casting process is one of the most common manufacturing processes of high complexity and precise parts. The challenge of the process in most cases is the homogenity of the castings material, which is influenced by several controllable parameters, such as speeds, pressures, temperatures, and changeover points between phases [1-8].

Our previous published results identified causes that affect the homogenity of certain aluminium high pressure die cast parts and leaded to the improvement of die casting process of automotive gearbox suspension brackets [9-10].

Present research work focuses on the material homogenity improvement by reduction of porosity, internal cold flow and shrinkage porosity, using squeeze pin technology. The scope of the squeeze pin is, by applying it in a massive area (big alloy volume), to modify the structure and density of the part during solidification stage. The homogenity levels were analyzed from the perspective of current standards [1114]. ASTM E505 - Reference radiographs for inspection of aluminium and magnesium die castings (C) 2019 Published by University Press. This is an open Attribution-NonCommercial-NoDerivs License (http://cre
[13] was used as reference standard for the results interpretation.

\section{Materials and methods}

The experiments were designed for the suspension bracket area of a part produced from $\mathrm{AlSi} 9 \mathrm{Cu} 3(\mathrm{Fe})$ with high pressure die casting technology, which concentrates a big volume of alloy due to functional design reasons.

This massive bracket area of the part with normal hole precast high pressure die cast process presents shrinkage porosity problems as well as internal cold flows, fact well known and predicted from solidification simulation phase with Flow3D software, as indicated in the Figure 1.

The tests were planned with a mold equipped with squeeze pin and related guiding bush, as well as hydraulic cylinder connected to the high pressure die cast machine, an Italpresse $1650 \mathrm{Tn}$ machine with possibility to control and monitor the squeeze time in and out through its shot control system and program connected to PC [15-23]. Analyze of samples was performed on an MU2000 Yxlon X-ray machine. 


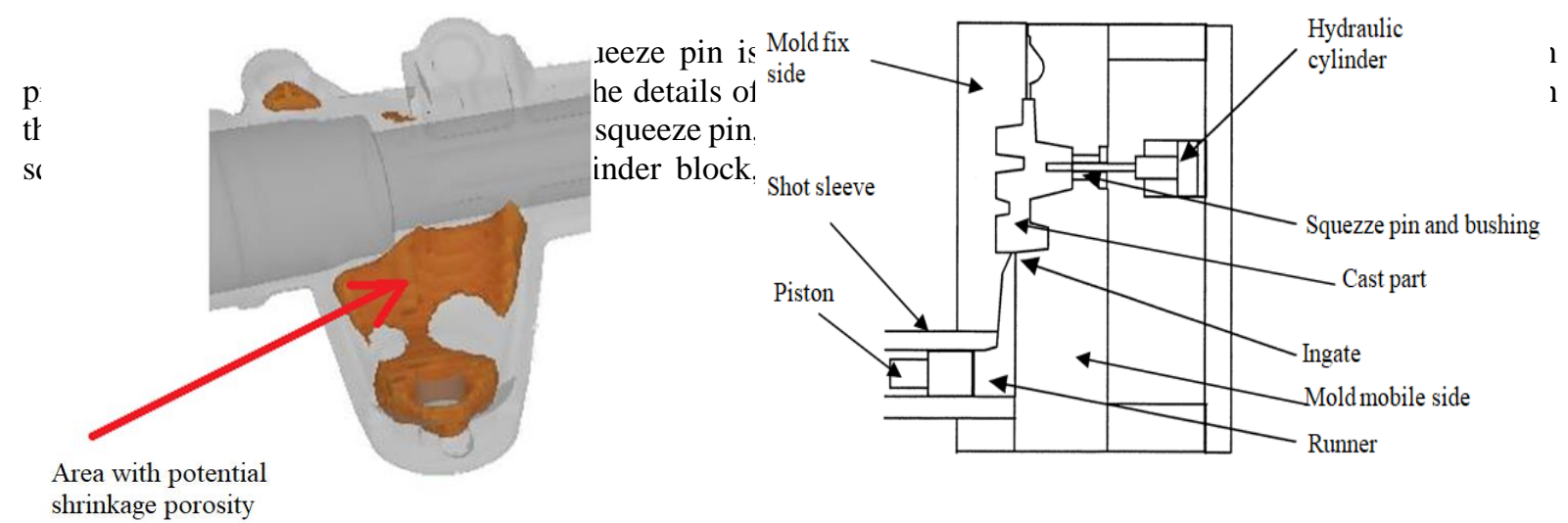

Fig. 1: Solidification simulation with Flow 3D software

Fig. 2: Schematic solution of the mold with squeeze pin

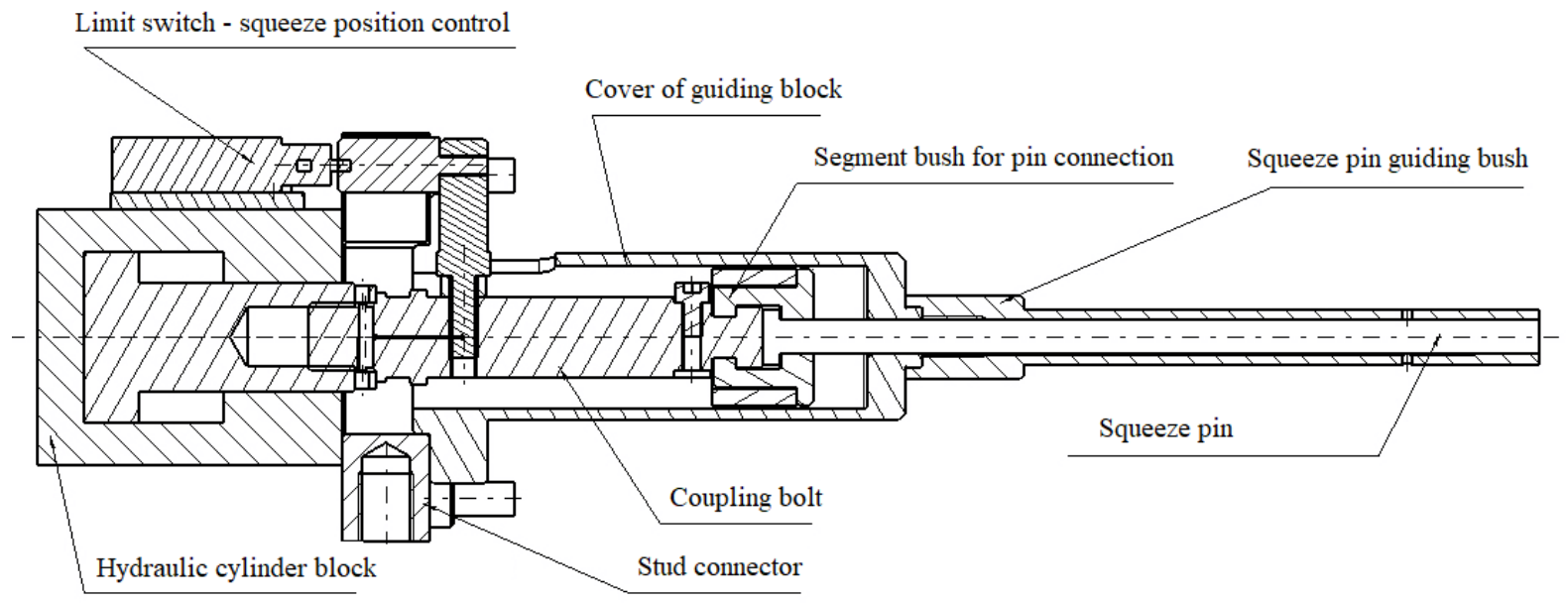

Fig. 3: Details of the squeeze design

Several dimensions - diameters and active lengths - of the squeeze pin, as well as different squeeze times, summarized in the Table 1, have been planned for the experimental test.

Table 1: Test plan

\begin{tabular}{|c|c|c|c|c|}
\hline Test number & Test code & $\begin{array}{c}\text { Squeeze pin } \\
\text { diameter }[\mathrm{mm}]\end{array}$ & $\begin{array}{c}\text { Squeeze } \\
\text { depth }[\mathrm{mm}]\end{array}$ & Squeeze time [s] \\
\hline \multirow{6}{*}{1} & 10_15_0 & \multirow{6}{*}{10} & \multirow{6}{*}{15} & 0 \\
\hline & $10 \_15 \_0.5$ & & & 0.5 \\
\hline & $10 \_15 \_1$ & & & 1 \\
\hline & $10 \_15 \_1.5$ & & & 1.5 \\
\hline & $10 \_15 \_2$ & & & 2 \\
\hline & $10 \_15 \_2.5$ & & & 2.5 \\
\hline \multirow{6}{*}{2} & 10_7.5_0 & \multirow{6}{*}{10} & \multirow{6}{*}{7.5} & 0 \\
\hline & $10 \_7.5 \_0.5$ & & & 0.5 \\
\hline & $10 \_7.5 \_1$ & & & 1 \\
\hline & $10 \_7.5 \_1.5$ & & & 1.5 \\
\hline & $10 \_7.5 \_2$ & & & 2 \\
\hline & 10_7.5_2.5 & & & 2.5 \\
\hline \multirow{6}{*}{3} & $9 \_15 \_0$ & \multirow{6}{*}{9} & \multirow{6}{*}{15} & 0 \\
\hline & $9 \_15 \_0.5$ & & & 0.5 \\
\hline & $9 \_15 \_1$ & & & 1 \\
\hline & $9 \_15 \_1.5$ & & & 1.5 \\
\hline & $9 \_15 \_2$ & & & 2 \\
\hline & $9 \_15 \_2.5$ & & & 2.5 \\
\hline
\end{tabular}




\begin{tabular}{|c|c|c|c|c|}
\hline \multirow{6}{*}{4} & 9_7.5_0 & \multirow{6}{*}{9} & \multirow{6}{*}{7.5} & 0 \\
\hline & $9-7.5 \_0.5$ & & & 0.5 \\
\hline & 9_7.5_1 & & & 1 \\
\hline & 9_7.5_1.5 & & & 1.5 \\
\hline & $9-7.5 \_2$ & & & 2 \\
\hline & 9_7.5_2.5 & & & 2.5 \\
\hline \multirow{6}{*}{5} & 8_15_0 & \multirow{6}{*}{8} & \multirow{6}{*}{15} & 0 \\
\hline & $8 \_15 \_0.5$ & & & 0.5 \\
\hline & $8 \_15 \_1$ & & & 1 \\
\hline & $8 \_15 \_1.5$ & & & 1.5 \\
\hline & 8_15_2 & & & 2 \\
\hline & $8 \_15 \_2.5$ & & & 2.5 \\
\hline \multirow{6}{*}{6} & 8_7.5_0 & \multirow{6}{*}{8} & \multirow{6}{*}{7.5} & 0 \\
\hline & 8_7.5_0.5 & & & 0.5 \\
\hline & $8 \_7.5 \_1$ & & & 1 \\
\hline & 8_7.5_1.5 & & & 1.5 \\
\hline & $8 \_7.5 \_2$ & & & 2 \\
\hline & 8_7.5_2.5 & & & 2.5 \\
\hline
\end{tabular}

\section{Results and discussion}

Each test has been performed according to the test plan. 10 samples have been produced in serial conditions for each test code with the corresponding parameters, by maintaining at the same level the values of the other process parameters, and varying only the parameters of the squeeze pin: diameter, depth and time.
The samples have been analyzed on an X-ray machine adjusted to a voltage of $115 \mathrm{kV}$ and intensity of $10 \mathrm{~mA}$. Radioscopy pictures have been captured at scale $2: 1$.

The representative radioscopy pictures captures of Test 3 - diameter of squeeze pin $9 \mathrm{~mm}$, depth $15 \mathrm{~mm}$ and squeeze times $0 \mathrm{~s}, 0.5 \mathrm{~s}, 1 \mathrm{~s}, 1.5 \mathrm{~s}, 2 \mathrm{~s}$, and $2.5 \mathrm{~s}$ are summarized in Figure 4.

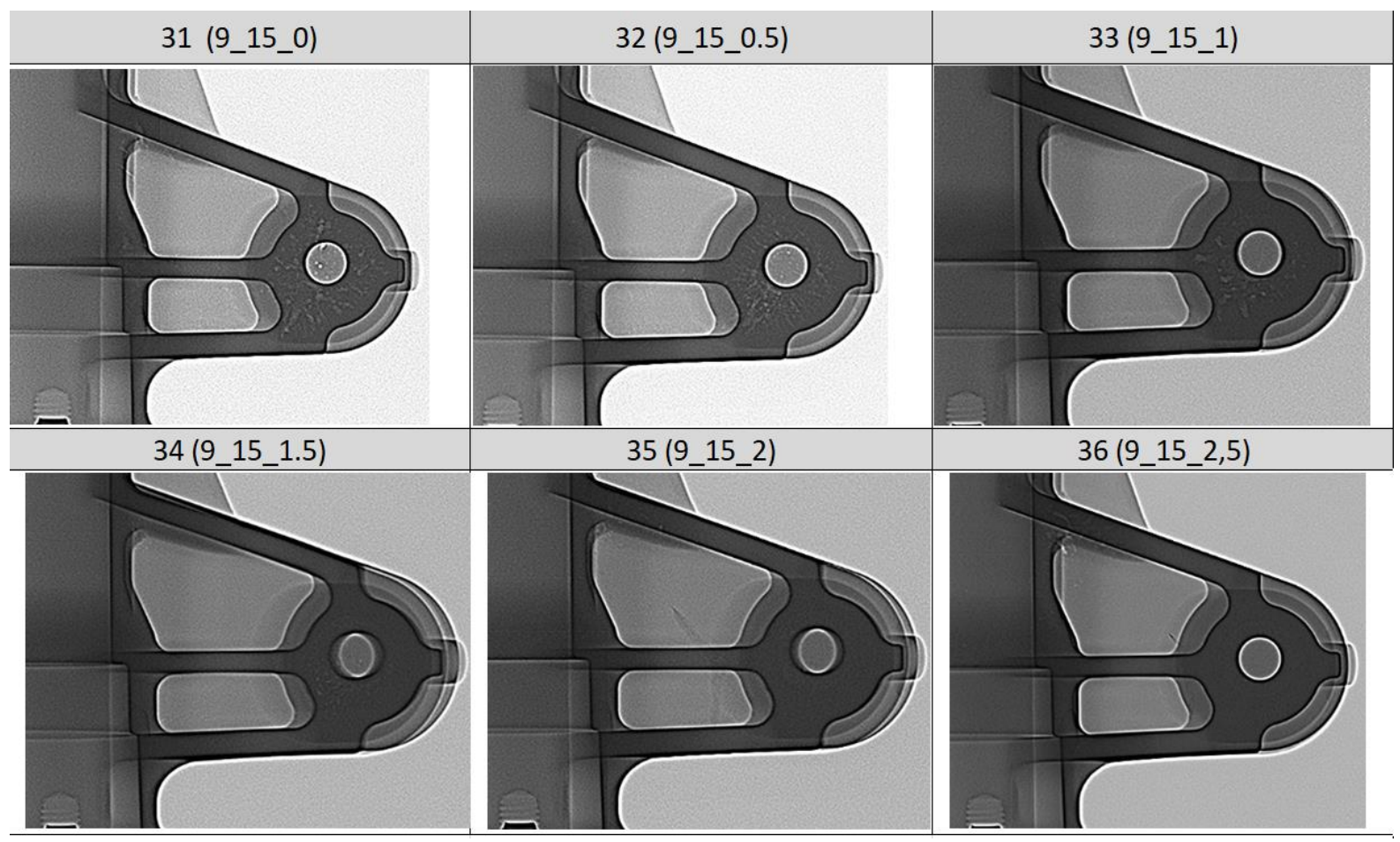

Fig. 4: Representative radioscopy pictures captures of Test 3

The representative radioscopy pictures captures of Test 4 - diameter of squeeze pin $9 \mathrm{~mm}$, depth $7.5 \mathrm{~mm}$ and squeeze times $0 \mathrm{~s}, 0.5 \mathrm{~s}, 1 \mathrm{~s}, 1.5 \mathrm{~s}, 2 \mathrm{~s}$, and $2.5 \mathrm{~s}$ are summarized in Figure 5. For each test 60 samples have been produced; totally for tests 1, 2, 3, 4, 5 and 6 , 360 samples have been produced. 
In case of all the tests for all samples the tendency of shrinkage presence and its dependency on squeeze time parameter can be observed. The appearance of a dark line can be observed at 1.5 - 2 seconds squeeze time delay in most of the cases with squeeze depth 15 $\mathrm{mm}$. Table 2 presents the summary of all test results.

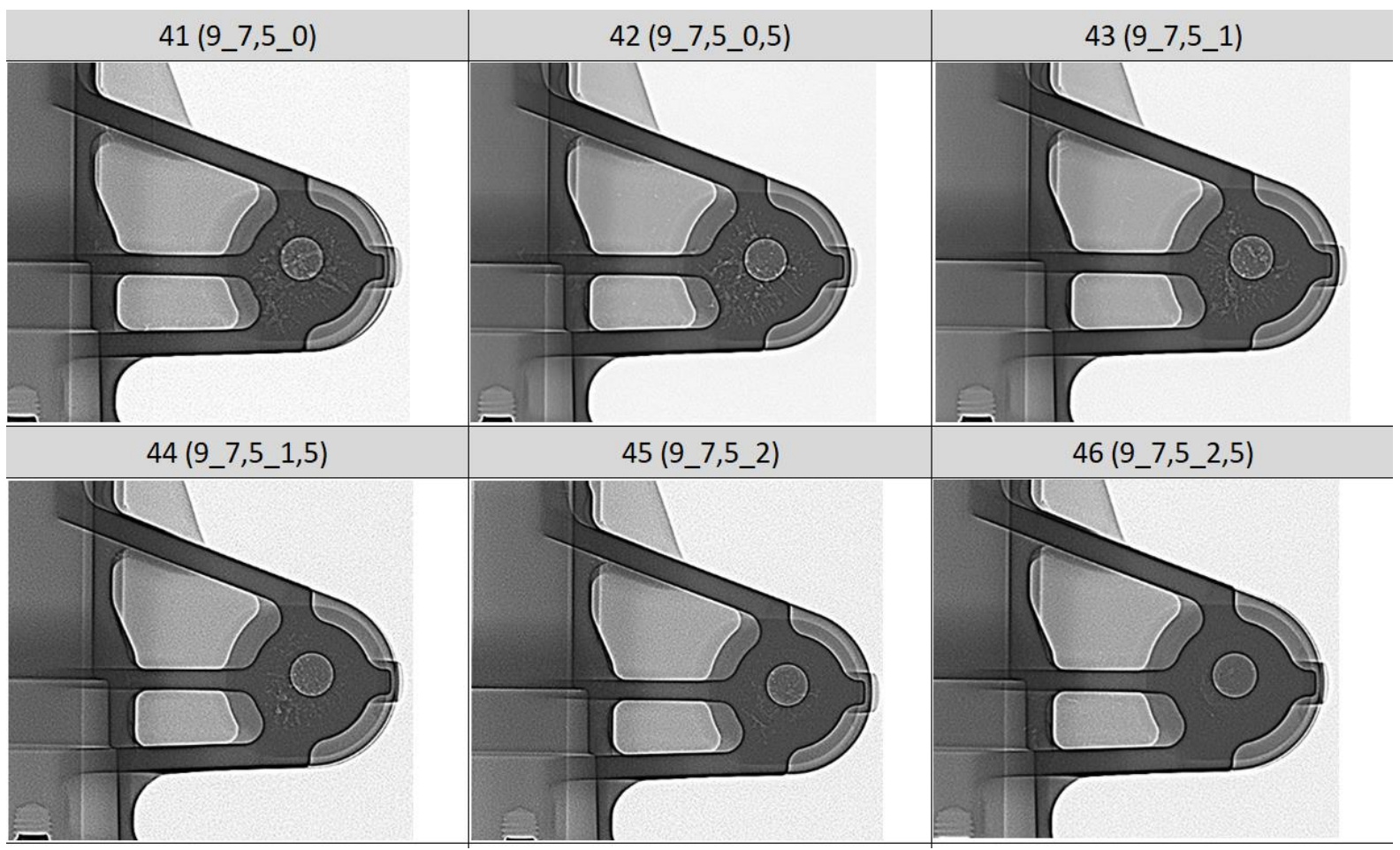

Fig. 5: Representative radioscopy pictures captures of Test 4

Table 2: Summary of all tests results

\begin{tabular}{|c|c|c|c|c|c|c|}
\hline $\begin{array}{c}\text { Test } \\
\text { number }\end{array}$ & Test code & $\begin{array}{c}\text { Squeeze pin } \\
\text { diameter }[\mathrm{mm}]\end{array}$ & $\begin{array}{c}\text { Squeeze } \\
\text { depth }[\mathrm{mm}]\end{array}$ & $\begin{array}{c}\text { Squeeze } \\
\text { time }[\mathrm{s}]\end{array}$ & $\begin{array}{c}\text { Shrinkage level } \\
\text { Target ASTM } \\
\text { E505 Level } 1\end{array}$ & $\begin{array}{l}\text { Dark line } \\
\text { presence }\end{array}$ \\
\hline \multirow{6}{*}{1} & 10_15_0 & \multirow{6}{*}{10} & \multirow{6}{*}{15} & 0 & NOK & no line \\
\hline & $10 \_15 \_0.5$ & & & 0.5 & NOK & no line \\
\hline & $10 \_15 \_1$ & & & 1 & NOK & no line \\
\hline & $10 \_15 \_1.5$ & & & 1.5 & OK & Line present \\
\hline & $10 \_15 \_2$ & & & 2 & OK & Line present \\
\hline & $10 \_15 \_2.5$ & & & 2.5 & OK & Line present \\
\hline \multirow{6}{*}{2} & 10_7.5_0 & \multirow{6}{*}{10} & \multirow{6}{*}{7.5} & 0 & NOK & no line \\
\hline & 10_7.5_0.5 & & & 0.5 & NOK & no line \\
\hline & $10 \_7.5 \_1$ & & & 1 & NOK & no line \\
\hline & 10_7.5_1.5 & & & 1.5 & NOK & no line \\
\hline & $10 \_7.5 \_2$ & & & 2 & Limit OK & Line present \\
\hline & 10_7.5_2.5 & & & 2.5 & OK & Line present \\
\hline \multirow{6}{*}{3} & $9 \_15 \_0$ & \multirow{6}{*}{9} & \multirow{6}{*}{15} & 0 & NOK & no line \\
\hline & 9_15_0.5 & & & 0.5 & NOK & no line \\
\hline & $9 \_15 \_1$ & & & 1 & NOK & no line \\
\hline & 9_15_1.5 & & & 1.5 & OK & Line present \\
\hline & $9 \_15 \_2$ & & & 2 & OK & Line present \\
\hline & 9_15_2.5 & & & 2.5 & OK & Line present \\
\hline \multirow{6}{*}{4} & 9_7.5_0 & \multirow{6}{*}{9} & \multirow{6}{*}{7.5} & 0 & NOK & no line \\
\hline & 9_7.5_0.5 & & & 0.5 & NOK & no line \\
\hline & 9_7.5_1 & & & 1 & NOK & no line \\
\hline & 9_7.5_1.5 & & & 1.5 & NOK & no line \\
\hline & 9_7.5_2 & & & 2 & NOK & no line \\
\hline & 9_7.5_2.5 & & & 2.5 & NOK & no line \\
\hline
\end{tabular}




\begin{tabular}{|c|c|c|c|c|c|c|}
\hline \multirow{6}{*}{5} & 8_15_0 & \multirow{6}{*}{8} & \multirow{6}{*}{15} & 0 & NOK & no line \\
\hline & 8_15_0.5 & & & 0.5 & NOK & no line \\
\hline & 8_15_1 & & & 1 & NOK & no line \\
\hline & 8_15_1.5 & & & 1.5 & Some OK & Line present \\
\hline & $8 \_15 \_2$ & & & 2 & Some OK & Line present \\
\hline & $8 \_15 \_2.5$ & & & 2.5 & Limit OK & Line present \\
\hline \multirow{6}{*}{6} & 8_7.5_0 & \multirow{6}{*}{8} & \multirow{6}{*}{7.5} & 0 & NOK & No line \\
\hline & 8_7.5_0.5 & & & 0.5 & NOK & No line \\
\hline & $8 \_7.5 \_1$ & & & 1 & NOK & No line \\
\hline & 8_7.5_1.5 & & & 1.5 & NOK & No line \\
\hline & 8_7.5_2 & & & 2 & NOK & No line \\
\hline & $8 \_7.5 \_2.5$ & & & 2.5 & NOK & No line \\
\hline
\end{tabular}

Scope of pin diameter and depth is to compensate volume. In this respect and also based on the results of the tests is evident that the shrinkage level became better and achieves the standard requirement at short squeeze delay time of 1.5 seconds. It is the case of test 1.4. with pin diameter $10 \mathrm{~mm}$, squeeze depth $15 \mathrm{~mm}$ and squeeze time delay 1.5 seconds.

With smaller pin diameter and reduced squeeze depth the standard requirement was not achieved. It is the case of test 6.6. with pin diameter $8 \mathrm{~mm}$, squeeze depth $7.5 \mathrm{~mm}$ and squeeze time delay of 2.5 seconds.

In case of the same pin diameter and depth we can observe the tendency and dependency of improvement of material homogenity with the increase of the squeeze time delay: as longer is the delay the better is the homogenity. This dependency is reflected in the captures from Figure 4 and 5.

As a secondary effect the appearance of a dark line can be observed. Its dependence is also direct with the bigger volume compensation and delay of the squeeze time: as longer is the delay the bigger is the size of the dark line. This dark line looks compact, but different as the rest of the area nearby. It might be a macro segregation of the alloying elements as a secondary effect of the resulted pressures and temperatures. Current standards don't evaluate the category level of this phenomenon.

The study of this phenomenon will be the subject of a future research work as well as its influence on the casting mechanical properties. Other future research directions would be:

- assessment of the alloy density in the squeezed area;

- determination of the hardness in the squeezed area;

- characterization of the chemical composition of the dark line area.

\section{Conclusions}

The use of squeeze pins is a practical method of material homogenity improvement for parts with high risk of shrinkage porosity resulted also from flow and solidification simulations for the high material volume areas.

The additional pressure coming from the squeeze pins have as a direct effect higher density of material and appearance of dark lines. This is normal and direct effect of the additional pressure applied during solidification phase.

The tests performed show the "indirect" relation between the dark lines and porosity. When dark lines do not appear, squeeze pin effect is smaller and porosity level is increased. When squeeze pin effect is better, dark lines appear naturally but only in this situation porosity level requested can be achieved.

\section{Acknowledgement}

This work was partially supported by the UMFST "GE Palade" Advanced Technologies for Design and Assisted Manufacturing (TAPFA) Research Center.

\section{References}

[1] Bellisario, D., Boschetti, A., Constanza, G., Tata Maria, E., Quadrini, F., and Santo, L. (2012), Squeeze Casting of Al-Si Alloys, in Recent Researches in Metallurgical Engineering - From Extraction to Forming, Ed. Mohammad Nusheh, InTech Open, pp. 161-186.

[2] Reikher, A., Barkhudarov, M.R. (2007), Casting: An analytical approach, in Series: Engineering Materials and Processes, Ed. Springer-Verlag London.

[3] Adamane, A.R., Arnberg, L., Fiorese, E. et al. (2015), Influence of Injection Parameters on the Porosity and Tensile Properties of HighPressure Die Cast Al-Si Alloys: A Review, International Journal of Metalcasting, vol. 9(1), pp. 43-53.

[4] Dong, X., Yang, H., Zhu, X, Ji, S.,(2019), High strength and ductility aluminium alloy processed by high pressure die casting, Journal of Alloys and Compounds, vol. 773, pp. 86-96.

[5] Jiao, X.Y, et. Al, (2019), Influence of slow-shot speed on PSPs and porosity of AlSi17Cu2.5 alloy during high pressure die casting, Journal of Materials Processing Technology, vol. 268, pp. 63-69.

[6] Apparao, K.c., Birru, A.K, (2017), Optimization of Die casting process based on Taguchi approach, Materials Today, vol. 4(2A), pp.18521859. 
[7] Jahangiri, A., Marashi, S.H.P., Mohammadaliha, M, Ashofte, V., (2017) The effect of pressure and pouring temperature on the porosity, microstructure, hardness and yield stress of AA2024 aluminum alloy during the squeeze casting process, Journal of Materials Processing Technology, vol. 245, pp. 1-6.

[8] Battaglia, E., Bonollo, F., Timelli, G., Fiorese, E., Kral, G., (2016), Correlation between process, microstructure and properties in high pressure die casting aluminium-silicon alloys, Advances in Materials and Processing Technologies, vol. 3(1), pp. 111-124.

[9] Peti, F., Grama, L., (2011), Analyse of the possible causes of porosity type defects in aluminium high pressure die cast parts, Scientific Bulletin of the „Petru Maior” University of Târgu Mureş, vol. 8 (XXV), no. 1, pp. 41-44.

[10] Peti, F., Grama L., (2012), Researches concerning constructive and technological improvements of automotive gearbox suspension brackets, Proceedings of the 6th Interdisciplinarity in Engineering International Conference InterEng-2012, "Petru Maior" University Press, pp. 87-92.
[11] SR EN 1706 - Aluminium and aluminium alloys, (2000).

[12] DIN 1688 - Tolerances for pressure die casting, (1986).

[13] ASTM E505 - Reference Radiographs for Inspection of Aluminium and Magnesium die castings, 2002.

[14] VDG Specification P201 - Porosity of Metal Castings, 2002.

[15] Company documentation CATIA, 2012.

[16] Fundamentos de la fundicion a presion, CIE C. Vilanova, Spain, 2008.

[17] Revision Tecnica del Producto, CIE C. Vilanova, Spain, 2008.

[18] Company documentation Bühler, 2010.

[19] Company documentation Idra, 2011.

[20] Company documentation Italpresse, 2011.

[21] Procedimiento IDT 05/1: Cuaderno de cargas de moldes, rev05, CIE Inyectametal, Spain, 2007.

[22] Norma Ingenieria NCV21006C-Tiempo llenado del molde, CIE C. Vilanova, Spain, 2006.

[23] Norma Ingenieria NCV21007B-Velocidad en el ataque, CIE C. Vilanova, Spain, 2006. 